The Journal of Laryngology \& Otology

http://journals.cambridge.org/JLO

Additional services for The Journal of Laryngology \& Otology:

Email alerts: $\underline{\text { Click here }}$

Subscriptions: $\underline{\text { Click here }}$

Commercial reprints: Click here

Terms of use : $\underline{\text { Click here }}$

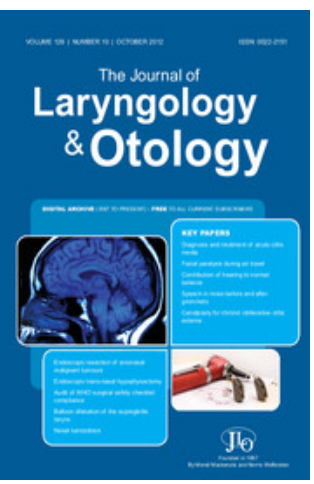

\title{
Quality of life of patients treated surgically for head and neck cancer
}

E. Jones, V. J. Lund, D. J. Howard, M. P. Greenberg and M. McCarthy

The Journal of Laryngology \& Otology / Volume 106 / Issue 03 / March 1992, pp 238 - 242

DOI: 10.1017/S0022215100119152, Published online: 29 June 2007

Link to this article: http://journals.cambridge.org/abstract S0022215100119152

How to cite this article:

E. Jones, V. J. Lund, D. J. Howard, M. P. Greenberg and M. McCarthy (1992). Quality of life of patients treated surgically for head and neck cancer. The Journal of Laryngology \& Otology, 106, pp 238-242 doi:10.1017/S0022215100119152

Request Permissions : $\underline{\text { Click here }}$ 


\title{
Quality of life of patients treated surgically for head and neck cancer
}

\author{
E. Jones, M.B., Ch.B., V. J. Lund, M.S., F.R.C.S., D. J. Howard, F.R.C.S., M. P. Greenberg, M.R.C.P., \\ M.R.C.PSYCH., M. MCCARTHY, M.R.C.P., M.F.C.M. (London)
}

\begin{abstract}
The quality of survival of 48 patients treated surgically for head and neck cancer was assessed using a problem-orientated self-administered questionnaire. The questionnaire was based on the European Organization for Research into the Treatment of Cancer (EORTC) core questionnaire to which a specific head and neck module was added. The following domains were studied: pain, fatigue, physical symptoms (gastrointestinal and 'other'), functional activity, psychological symptoms, overall physical condition and overall quality of life. For the analysis, five groups of patients were considered: laryngectomy $(n=15)$, pharyngolaryngoesophagectomy $(n=5)$, craniofacial procedure $(n=11)$, 'other operations' $(n=9)$ and patients with disease recurrence $(n=8)$. Each group identified different problem areas. Laryngectomees and 'other operation' patients reported relatively few problems, whereas patients with disease recurrence described difficulties in all of the domains examined. Symptoms of fatigue were common. Information collected in this way may facilitate improved rehabilitation and thus better quality of survival.
\end{abstract}

\section{Introduction}

Patients with head and neck cancer are rendered vulnerable to psychosocial problems because social interaction and emotional expression depends to a great extent upon the structural and functional integrity of the head and neck region (Breitbart and Holland, 1988). These individuals cannot hide their disfigurement which is constantly on view.

In 1985 approximately 5000 new cases of head and neck cancer were registered in the U.K. (Cancer Research Campaign, 1990). This represents an incidence rate of approximately 88 cases per million population. During 1988 , approximately 2,500 deaths in the U.K. were attributed to head and neck cancer (Cancer Research Campaign, 1989). Five year survival rates of patients with head and neck cancer are generally poor (Cancer Research Campaign, 1988) and treatment is more often palliative than curative. Length of survival alone is an unsatisfactory measure of the success of palliative treatment (Brinkley, 1985 ); the quality as well as the quantity of survival needs to be evaluated.

Quality of life is a difficult concept to define (Calman, 1984). However, there appears to be agreement in the literature with regard to its multidimensional nature (Flanagan, 1982; Smart and Yates, 1987). In order to assess quality of life, it needs to be broken down into its component parts and at least the following four aspects should be considered: physical complaints (somatic sensations, disease symptoms and treatment side effects), social functioning, psychological distress and functional status (Aaronson et al., 1988). Furthermore, quality of life may be more than just the sum of its component parts (De Haes and Van Knippenberg, 1985) and the inclusion of a global question regarding overall quality of life may capture information not covered by the more specific sets of items.

Several standardized instruments have been developed to measure quality of life and a number of reviews are available which examine the appropriateness of using these instruments with cancer patients (De Haes and Van Knippenberg, 1985; Clark and Fallowfield, 1986; Selby and Robertson, 1987; Maguire and Selby, 1989). No single instrument is likely to prove suitable for all purposes in all patients (Brinkley, 1985). In a detailed review, Maguire and Selby (1989) recommend that any instrument used to assess quality of life should be completed by the patient, easy and quick to fill in and score, valid and reliable and able to reflect changes over time. The EORTC (European Organization for Research into the Treatment of Cancer) core questionnaire (Aaronson et al., 1988) fulfils these criteria and has been designed for use in heterogenous groups of cancer patients. It is problem-orientated and functions as a standard quality of life instrument to which disease specific modules can be added.

Morris (1990) has reviewed quality of life studies in patients with head and neck malignancy. The majority of these studies have been descriptive and no study has employed standardized instruments. Most inquiries have focused on functional and physical dimensions, while psychosocial morbidity, if assessed at all, has been measured using inadequate or inappropriate methods. Information has often been collected using interviews with various categories of disability being rated by the interviewer rather than the patient and the majority of studies have included only those patients free of disease and hence with a positive treatment outcome. 
We have developed an instrument, based on the core EORTC quality of life questionnaire, to provide a measure for quality of life in patients with head and neck cancer. We report here the items chosen and the results of using the instrument in a retrospective study.

\section{Methods and subjects}

The EORTC core questionnaire (Aaronson et al., 1988) is designed to be self-administered and has been shown to be both easy and quick to complete (Maguire and Selby, 1989) and acceptable to patients. It consists of 34 items, 32 of which assess the domains of functional activity (role and personal functioning), psychological status, physical symptoms (related to both the disease and its treatment) and social functioning with the remaining two items measuring overall physical condition and overall quality of life. Items on functional activity comprise 'yes' or 'no' responses and are measured on a cumulative Guttmantype scale (Guttman, 1944), each item scoring 0 or 1. Questions regarding psychological status, physical symptoms and social functioning use a Likert-type four point scale (Likert, 1932) with responses ranging from 'not at all' to 'very much' (measured on a $0-3$ interval scale) while the items concerning overall physical condition and overall quality of life are measured on a seven point scale from 'excellent' to 'very poor' (on a 0-6 interval scale). By summation of individual item scores, each domain can be expressed numerically, with a high score indicating problems within that domain.

Eight of the items used in the core questionnaire to assess psychological status are taken from the Hospital Anxiety and Depression Scale (HADS) which was developed by Zigmond and Snaith (1983) specifically for use with physically sick populations. This instrument has two subscales, anxiety (seven items) and depression (seven items), and does not include items of a somatic nature which could be caused by physical disease as much as by mood disturbance. A shortened version (four items measuring anxiety and four depression) was incorporated in the EORTC questionnaire.

No head and neck module has, as yet, been published for use with the EORTC questionnaire. In order to develop such a module, interviews were conducted with 12 patients who had undergone surgery for head and neck malignancy more than three years previously (and hence not included in the pilot study). In addition, a head and

TABLE 1

SPECIFIC HEAD AND NECK ITEMS ADDED TO THE EORTC CORE QUESTIONNAIRE

Have you had trouble swallowing?

Do you take longer to eat a meal?

Do you eat less food?

Have you lost weight?

Has your sense of smell been affected?

Has your sense of taste been affected?

Have you had headaches?

Have you felt less able to perform sexual activities?

Have you had pain at the site of your operation?

Have you felt self-conscious about your appearance?

Have you felt isolated?

Have you had difficulty using your present voice to communicate with people?

Either: Has your vision been affected? or Have you had difficulty caring for your tracheostomy? neck literature review was undertaken and discussions were held with health professionals. A series of questions were produced which after further piloting and discussion with patients and professionals were reduced to the 14 items shown in Table I. Each item is scored on an interval scale of 0-3 ('not at all' to 'very much').

For the pilot study, 49 patients who had undergone surgical treatment for head and neck cancer at a tertiary referral centre (the Royal National Throat Nose and Ear Hospital, London) were each sent a postal questionnaire. Following two mailings, completed questionnaires were returned by 48 patients (a response rate of 98 per cent). The questionnaires were completed 4-26 months after surgery (mean 16 months). All patients were attending regular follow-up clinics and thus it was possible to identify those individuals in whom disease recurrence had been diagnosed at the time of completion of the questionnaire. Eight patients were known to have clinical disease recurrence at this time. Table II indicates both the operation which each patient underwent and the presence or absence of clinical disease recurrence. For the analysis patients were grouped as follows: laryngectomy (15), craniofacial procedure (11), pharyngolaryngoesophagectomy ('pull-up') (5), 'other operations' (9) and patients with clinical disease recurrence (8). Patients who had undergone hemiglossectomy $(n=4)$, tonsillectomy $(\mathrm{n}=3)$ or thyroidectomy $(\mathrm{n}=2)$ were included under 'other operations'. The sex distribution, age and time in months from operation to completion of the questionnaire for each of the five groups of patients are shown in Table III.

\section{Results}

Table IV shows the mean values obtained by each group of patients for each specific head and neck item. In each group different problem areas were identified; pharyngolaryngoesophagectomy patients described eatingand speech-related difficulties, craniofacial patients reported affected vision, headaches and diminished senses of taste and smell, laryngectomy patients described hyposmia and speech-related difficulties and patients with disease recurrence reported eating- and speech-related difficulties, self-consciousness and affected senses of smell and taste.

The individuals included under 'other operations' represent a heterogenous group of patients four of whom underwent hemiglossectomy, three tonsillectomy and two

\section{TABLE II}

NUMBER OF PATIENTS, WITH OR WITHOUT CLINICALLY-APPARENT DISEASE RECURRENCE, IN EACH OPERATION GROUP

\begin{tabular}{lcc}
\hline & $\begin{array}{c}\text { No disease } \\
\text { recurrence }\end{array}$ & $\begin{array}{c}\text { Disease } \\
\text { recurrence }\end{array}$ \\
\hline $\begin{array}{l}\text { Laryngectomy } \\
\text { Craniofacial }\end{array}$ & 15 & 4 \\
$\begin{array}{l}\text { Pharyngo-laryngo- } \\
\text { oesophagectomy (pull-up) }\end{array}$ & 5 & 2 \\
$\begin{array}{l}\text { Hemiglossectomy } \pm \text { neck } \\
\text { dissection }\end{array}$ & 4 & 1 \\
$\begin{array}{l}\text { Tonsillectomy } \pm \text { neck } \\
\text { dissection }\end{array}$ & 3 & 1 \\
$\begin{array}{l}\text { Thyroidectomy } \pm \text { neck } \\
\text { dissection }\end{array}$ & 2 & 0 \\
Total & $40(83 \%)$ & $8(17 \%)$ \\
\hline
\end{tabular}


TABLE III

DETAILS OF THE PATIENTS IN EACH OPERATION GROUP

\begin{tabular}{|c|c|c|c|c|c|c|}
\hline & Laryngectomy & Craniofacial & Pull-up & Other operations & Recurrence & Total \\
\hline Number & 15 & 11 & 5 & 9 & 8 & 48 \\
\hline $\mathrm{M}: \mathrm{F}$ & $12: 3$ & $7: 4$ & $2: 3$ & $8: 1$ & $6: 2$ & $35: 13$ \\
\hline Age in years (median) & $41-83(65)$ & $27-70(54)$ & $44.62(54)$ & $29-75(62)$ & $47-74(62)$ & $27-83(62)$ \\
\hline $\begin{array}{l}\text { Time in months from operation to } \\
\text { completion of questionnaire (mean) }\end{array}$ & $4-26(16)$ & $4-25(16)$ & $5-24(17)$ & $5-25(15)$ & $7-26(18)$ & $4-26(16)$ \\
\hline
\end{tabular}

thyroidectomy. The hemiglossectomy patients reported eating less food (mean 1.5), taking longer to eat a meal (mean 1.5), weight loss (mean 1.3) and speech related difficulties (mean 1.3). The tonsillectomy patients reported difficulty swallowing (mean 1.3) and loss of weight (mean 1.3) while the thyroidectomy patients did not score highly for any of the items.

Table V shows the mean values obtained by each group of patients when the items of the EORTC core questionnaire and the specific head and neck questions were grouped into nine domains. The items concerning ability to use one's present voice to communicate with others and feeling isolated were included under social functioning. Impaired social functioning was reported by pull-up patients and patients with disease recurrence. 'Other physical symptoms' included inquiries concerning shortness of breath, trouble sleeping, affected sense of taste and smell, headaches, feeling less able to perform sexual activities and either affected vision or difficulty caring for one's tracheostomy (depending on the operation undergone). Craniofacial patients and patients with recurrence reported significant difficulties within this domain. High levels of fatigue were described by patients who had undergone a pharyngolaryngoesophagectomy or a craniofacial procedure and also by patients with disease recurrence. In fact, patients with recurrence scored highly in all the domains studied.

Psychological symptoms were most marked in patients who had disease recurrence and those who had undergone a pull-up procedure. Analysing the eight items derived from the HADS; symptoms of anxiety were described to a greater degree than those of depression. The mean values reported by each treatment group for anxiety and depression (range $0-12$ ), respectively, were: 2.0 and 0.6 for laryngectomy patients, 3.6 and 1.7 for craniofacial patients, 5.0 and 3.6 for pull-up patients, 3.0 and 2.7 for patients who had undergone 'other operations' and 6.2 and 4.9 for patients with disease recurrence.
Laryngectomy patients scored well in all of the domains indicating that they reported few residual problems. We compared quality of life in the laryngectomy group with each of the other four treatment groups and found that craniofacial patients fared significantly worse in 4/7 domains, pull-up patients in 5/7, patients who had undergone 'other operations' in $0 / 7$ and patients with recurrence in $7 / 7$ when compared with laryngectomy patients.

\section{Discussion}

Since a patient's quality of life changes with progression from early symptomatic disease and problems related to treatment to progressive disease, and sometimes terminal illness (Smart and Yates, 1987), a measuring instrument should be both sensitive and able to reflect changes over time. The EORTC core questionnaire fulfils these criteria and hence provides a valuable tool to identify the different problems encountered at various stages of disease and/or its treatment.

The 98 per cent response rate achieved in this small pilot study suggests that the questionnaire used is acceptable to patients. In addition, all questionnaires returned were suitable for analysis which implies that the questionnaire is easy to understand and complete. The instrument appears to have face validity as illustrated by its ability to differentiate between the problems encountered by different treatment groups and also by the higher scores recorded in patients with disease recurrence and hence worse prognosis.

In our study, patients who had undergone laryngectomy scored well in all the domains studied, indicating that they reported relatively few residual problems. However, as would be expected, they reported speech related difficulties and these findings are consistent with the conclusions of previous studies (Dhillon et al., 1982; Olsen

TABLE IV

MEAN VALUES OBTAINED BY EACH OPERATION GROUP FOR THE SPECIFIC HEAD AND NECK ITEMS

\begin{tabular}{|c|c|c|c|c|c|}
\hline & $\begin{array}{l}\text { Laryngectomy } \\
\qquad(\mathrm{n}=15)\end{array}$ & $\begin{array}{l}\text { Craniofacial } \\
(\mathrm{n}=11)\end{array}$ & $\begin{array}{l}\text { Pull-up } \\
(\mathrm{n}=5)\end{array}$ & $\begin{array}{l}\text { Other operations } \\
\qquad(\mathbf{n}=9)\end{array}$ & $\begin{array}{l}\text { Patients with recurrence } \\
\qquad(\mathrm{n}=8)\end{array}$ \\
\hline Swallowing & 0.9 & 0.4 & 1.0 & 1.0 & 1.5 \\
\hline Speed of eating & 1.3 & 0.6 & 2.6 & 1.1 & 2.6 \\
\hline Eat less food & 0.6 & 0.4 & 2.0 & 1.1 & 2.1 \\
\hline Lost weight & 0.3 & 0.8 & 0.4 & 1.1 & 1.0 \\
\hline Smell affected & 2.1 & 2.4 & 1.4 & 0.0 & 2.2 \\
\hline Taste affected & 0.9 & 1.8 & 1.2 & 0.8 & 2.0 \\
\hline Headaches & 0.2 & 1.5 & 0.6 & 0.2 & 0.7 \\
\hline Speech & 1.5 & 0.0 & 2.0 & 0.6 & 1.6 \\
\hline Isolated & 0.6 & 0.5 & 1.8 & 0.3 & 0.9 \\
\hline Self-conscious & 0.4 & 0.6 & 0.6 & 0.3 & 1.5 \\
\hline Sexual activity & 0.6 & 0.6 & 2.7 & 0.7 & 2.3 \\
\hline Vision & 0.0 & 1.4 & 0.0 & 0.4 & 0.6 \\
\hline Pain at operation site & 0.3 & 1.0 & 0.6 & 0.6 & 1.0 \\
\hline Stoma care & 0.2 & na & 0.6 & na & 0.5 \\
\hline
\end{tabular}


TABLE V

MEAN VALUES OBTAINED BY EACH SURGICAL GROUP FOR EACH DOMAIN. THE LARYNGECTOMY GROUP WAS COMPARED WITH THE OTHER FOUR GROUPS USING WILCOXON RANK SUM TEST

\begin{tabular}{|c|c|c|c|c|c|c|c|c|c|}
\hline Domain & $\begin{array}{l}\text { No. of } \\
\text { core }\end{array}$ & $\begin{array}{l}\text { items } \\
\mathrm{H} \& \mathrm{~N}\end{array}$ & Range & $\begin{array}{l}\text { Laryngectomy } \\
\qquad(\mathrm{n}=15)\end{array}$ & $\begin{array}{c}\text { Craniofacial } \\
(n=11)\end{array}$ & $\begin{array}{l}\text { Pull-up } \\
(n=5)\end{array}$ & $\begin{array}{l}\text { Other operations } \\
\qquad(\mathrm{n}=9)\end{array}$ & $\begin{array}{l}\text { recurrence } \\
\quad(n=8)\end{array}$ & $\begin{array}{c}\text { Total } \\
(n=48)\end{array}$ \\
\hline Pain & 2 & 1 & $0-9$ & 0.7 & $2.5^{*}$ & 2.0 & 1.1 & $3.4 *$ & 1.8 \\
\hline Fatigue & 3 & 0 & $0-9$ & 1.7 & $4.1 * *$ & $4.4^{* *}$ & 2.6 & $6.2 * * *$ & 3.4 \\
\hline Gastrointestinal symptoms & 5 & 4 & $0-27$ & 4.7 & 3.3 & $9.0^{*}$ & 6.2 & $12.4 * * *$ & 6.4 \\
\hline Other physical symptoms & 2 & 5 & $0-21$ & 4.9 & $8.6^{* *}$ & $7.6^{*}$ & 3.2 & $11.0 * * *$ & 6.7 \\
\hline Psychological symptoms & 10 & 1 & $0-33$ & 3.3 & $8.5^{*}$ & $11.0^{* *}$ & 7.3 & $14.5^{* * *}$ & 7.9 \\
\hline Social functioning & 3 & 2 & $0-15$ & 3.0 & 2.5 & 6.4 & 2.3 & $8.4^{* *}$ & 4.1 \\
\hline Functional activity & 7 & 0 & $0-7$ & 0.7 & 0.8 & $2.8^{*}$ & 1.1 & $3.9 * * *$ & 1.5 \\
\hline Overall physical condition & 1 & 0 & $0-6$ & 1.0 & 2.0 & 2.2 & 2.0 & $3.2 * * *$ & 1.9 \\
\hline Overall quality of life & 1 & 0 & $0-6$ & 1.1 & 1.7 & 1.6 & 1.3 & $3.5 * * *$ & 1.8 \\
\hline
\end{tabular}

${ }^{*} \mathrm{p}<0.05 ;{ }^{*} \mathrm{p}<0.01 ; * * * \mathrm{p}<0.001$.

and Shedd, 1978; Natvig, 1983a, 1983b; Pruyn et al., 1986). For example, Dhillon et al., (1982) found that 16 out of 35 laryngectomy patients studied reported constant difficulty in making themselves understood or were completely unable to speak but they experienced relatively few problems in the other areas studied (eating, cosmetic, employment and social functioning) while Natvig (1983b) found that loss of their normal voice was the greatest problem for 40 per cent of the 186 laryngectomy patients he interviewed. Laryngectomy patients also described a markedly affected sense of smell (and hence, taste) reflecting their inability to sniff post-operatively.

The craniofacial procedure represents a relatively recent innovation within head and neck surgery which has improved prognosis and is associated with low post-operative morbidity and good cosmesis (Cheesman et al., 1986; Lund and Harrison, 1988). However, in this small study, patients who had undergone this procedure reported significant problems in a number of areas including the presence of headaches, altered (usually blurred) vision, fatigue, pain and anxiety. These patients also reported a significant hyposmia (with concomitant hypogeusia) as an inevitable consequence of surgical resection of the cribriform plate and olfactory epithelium.

Cancer of the hypopharynx often presents late and has a poor prognosis. The treatment of choice for this condition in this unit is a total pharyngolaryngoesophagectomy with gastric transposition (Harrison and Thompson, 1986) and, not surprisingly, patients who had undergone this extensive procedure reported significant symptoms of a gastrointestinal nature. However, despite their inability to sniff, diminished sense of smell (and taste) was described less frequently by pull-up patients than by laryngectomees. Patients with cancer of the hypopharynx experience marked dysphagia prior to surgical intervention and it can be hypothesized that the post-operative improvement in swallowing overshadows any alteration of smell and taste. This small group of patients also reported high levels of fatigue, functional limitation, speech related problems and feelings of isolation.

Patients who had undergone hemiglossectomy reported speech related difficulties as well as problems with eating and these findings are consistent with the results of other studies (Olsen and Shedd, 1978; David and Barritt, 1982).

Patients with clinical disease recurrence at the time of completion of the questionnaire were included in the study but as a separate group $(\mathrm{n}=8)$, as it was felt that their disease experience would be different from that of patients without recurrence. They reported high levels of problems in all of the domains studied and rated their overall physical condition and overall quality of life as being poor. Similar findings were reported by Drettner and Ahlbom (1983) in their study of 52 patients with head and neck cancer. They differentiated between patients with a good/bad prognosis and found that patients with a poor prognosis reported a low health index and poor quality of life.

Psychiatric morbidity has been estimated to affect between 20 per cent and 35 per cent of all cancer patients (Feinnmann and Hapwood, 1990); however, it is often ignored as the distress is judged to be inevitable and understandable (Massie and Holland, 1984). Psychological problems may, in addition to adversely affecting quality of life, interfere with the treatment and rehabilitation of patients with head and neck malignancy. In our study, pull-up patients and patients with disease recurrence described high levels of both anxiety and depression, with symptoms reflecting anxiety predominating. In the postoperative period, high levels of anxiety may be provoked by concerns about ability to communicate with others, altered appearance, adaptation to dysfunction and/or fears of disease recurrence (Breitbart and Holland, 1988). It is estimated that approximately 25 per cent of cancer patients suffer from depression (Derogatis et al., 1983; Bukberg et al., 1984) and patients with head and neck malignancy are at even greater risk due to the mutilating surgery (Breitbart and Holland, 1988). Morton et al. (1984) reported the presence of depression in 40 per cent of 48 the patients they interviewed with buccopharyngeal malignancy. High levels of fatigue were reported by our study group. This has also been described in other studies (Krouse et al., 1989) and could represent a somatic manifestation of psychological distress.

Survival rates for patients with head and neck malignancy have changed little over the past 25 years but advances in reconstructive surgery together with increased emphasis on rehabilitation have almost certainly improved the quality of that survival (Stell and McCormick, 1985). Information collected using the problem-orientated EORTC instrument will enhance our understanding of the difficulties patients may encounter which, in turn, may facilitate improved rehabilitation and better quality of survival.

The instrument could also be used to assess quality of life of patients receiving radiotherapy. It would be necessary to make minor alterations to the head and neck module as certain of the items are applicable only to surgical patients (e.g. pain at operation site and difficulty with tra- 
cheostomy) and inquiries about side-effects associated with radiotherapy would need to be included (for example, dry/sore skin or mouth). However, the core questionnaire would remain unchanged and therefore it would be possible to assess the quality of life of patients receiving different treatment modalities.

Retrospective studies have a number of drawbacks including over-representation of patients with positive treatment outcomes (Pruyn et al., 1986) and absence of information on pre-existing (pre-treatment) problems which may influence quality of life (Morris, 1990). For these reasons, we have commenced a prospective study in which patients complete the questionnaire pre-operatively and three, six and 12 months post-operatively.

\section{Acknowledgements}

We would like to thank Dr Sam Ahmedzai for advice in using the EORTC questionnaire, and Lawrence Goldie for his advice.

\section{References}

Aaronson, N. K., Bullinger, M., Ahmedzai, S. (1988) A modular approach to quality of life assessment in cancer clinical trials. Recent Results in Cancer Research. 111: 231-249.

Breitbart, W., Holland, J. (1988) Psychosocial aspects of head and neck cancer. Seminars in Oncology, 15: 61-69.

Brinkley, D. (1985) Quality of life in cancer trials. British Medical Journal, 291: 685-686.

Bukberg, J., Penman, D., Holland, J. (1984) Depression in hospitalized cancer patients. Psychosomatic Medicine, 46: 199-212.

Calman, K. C. (1984) Quality of life in cancer patients-an hypothesis. Journal of Medical Ethics, 10: 124-127.

Cancer Research Campaign (1988) Factsheet 9.

Cancer Research Campaign (1989) Factsheet 3.

Cancer Research Campaign (1990) Factsheet 1.

Cheesman, A. D., Lund, V. J., Howard, D. J. (1986) Craniofacial resection for tumours of the nasal cavity and paranasal sinuses. Head and Neck Surgery, 8: 429-435.

Clark, A., Fallowfield, L. J. (1986) Quality of life measurements in patients with malignant disease: a review. Journal of the Royal Society of Medicine, 79: 165-169.

David, D. J., Barritt, J. A. (1982) Psychosocial implications of surgery for head and neck cancer. Clinics in Plastic Surgery, 9: $327-335$.

De Haes, J. C. J. M., Van Knippenberg, F. C. E. (1985) The quality of life of cancer patients. A review of the literature. Social Science and Medicine, 20: 809-817.

Derogatis, L. R., Morrow, G. R., Fetting, J., Renman, D., Piasetsky, S., Schmale, A. M., Henrichs, M., Carnicke, C. L. M. (1983) The prevalence of psychiatric disorders among cancer patients. Journal of the American Medical Association, 249: 751-757.

Dhillon, R. S., Palmer, B. V., Pittam, M. R., Shaw, H. J. (1982) Rehabilitation after major head and neck surgery-the patients' view. Clinical Otolargyngology, 7: 319-324.
Drettner, B. Ahlbom, A. (1983) Quality of life and state of health for patients with cancer in the head and neck. Acta Otolaryngologica. 96: $307-314$.

Feinnmann, C., Hapwood, P. (1990) Emotional disturbance of patients with functional symptoms. Journal of the Royal Society of Medicine 83: 596-597.

Flanagan, J. C. (1982) Measure of quality of life. Current state of the art. Archives of Physical Medicine and Rehabilitation, 63: 56-59.

Guttman, L. A. (1944) A basis for scaling qualitative data. American Sociological Review, 9: 139-150.

Harrison, D. F. N., Thompson, A. E. (1986) Pharyngolaryngoesophagectomy with pharyngogastric anastomosis for cancer of the hypopharynx: review of 101 operations. Head and Neck Surgery, 8: $418-428$.

Krouse, J. H., Krouse, H. J., Fabian, R. L. (1989) Adaptation to surgery for head and neck cancer. Laryngoscope, 99: 789-794.

Likert, R. (1932) A technique for the measurement of attitudes. Archiv Fur Psychologie, 140: 1-55.

Lund, V. J., Harrison, D. F. N. (1988) Craniofacial resection for tumours of the nasal cavity and paranasal sinuses. American Journal of Surgery, 156: 187-190.

Maguire, P., Selby, P. (1989) Assessing quality of life in cancer patients. British Journal of Cancer, 60: $437-440$.

Massie, M. J., Holland, J. C. (1984) Diagnosis and treatment of depression in the cancer patient. Journal of Clinical Psychology. 45: 25-28.

Morris, J. (1990) The quality of life of head and neck cancer patients: a review of the literature. Centre for Health Economics, University of York

Morton, R.P., Davies, A. D. M., Baker, J., Baker, G. A., Stell, P. M. (1984) Quality of life in treated head and neck cancer patients. A preliminary report. Clinical Otolaryngology, 9: 181-185.

Natvig, K. (1983a) Laryngectomees in Norway. Study No. 1: Social, personal, and behavioural factors related to present mastery of the laryngectomy event. Journal of Otolaryngology, 12: 155-162.

Natvig, K. (1983b) Laryngectomees in Norway. Study No. 5: Problems of everyday life. Journal of Otolaryngology, 13: 15-22.

Olsen, M. L., Shedd, D. P. (1978) Disability and rehabilitation in head and neck cancer patients after treatment. Head and Neck Surgery, 1: 52-58.

Pruyn, J. F. A., de Jong, P. C., Bosman, L. J., van Poppel, J. W. M. J., van den Borne, H. W., Ryckman, R. M., de Meij, K. (1986) Psychological aspects of head and neck cancer-a review of the literature. Clinical Otolaryngology, 11: 469-474.

Selby, P., Robertson, B. (1987) Measurement of quality of life in patients with cancer. Cancer Surveys, 6: 521-543.

Smart, C. R., Yates, J. W. (1987) Quality of life. Cancer, 60: $620-622$

Stell, P. M., McCormick, M. S. (1985) Cancer of the head and neck: Are we doing any better? [letter]. Lancet, 2: 1127.

Zigmond, A. S., Snaith, R. P. (1983) The hospital anxiety and depression scale. Acta Psychiatrica Scandinavica, 67: 361-370.

Address for correspondence:

E. Jones, M.B., Ch.B.,

Department of Community Medicine,

University College London,

66-72 Gower Street,

London WC1E 6EA.

\section{Key words: Head and neck neoplasms; Surgery; Quality of life}

